\title{
NECROPOLÍTICAS DEL MERCADO: CUERPOS CANIBALIZADOS, GÉNERO Y RESISTENCIA EN MANO DE OBRA (2002) E IMPUESTO A LA CARNE (2010), DE DIAMELA ELTIT
}

\author{
Market Necropolitics: Cannibal Bodies, Gender and Resistance in Diamela Eltit's "Mano de \\ Obra" (2002) and "Impuesto a la Carne" (2010)
}

\author{
Paola Susana Solorza \\ learningspanishba@hotmail.com \\ Universidad de Buenos Aires - Argentina
}

Recibido: 26-02-2017

Aceptado: 22-04-2017

\section{Resumen}

El presente artículo propone una reflexión sobre las prácticas de coacción y exclusión que implementa la necropolítica del modelo neoliberal, a través del análisis de dos novelas de la escritora chilena Diamela Eltit: Mano de obra (2002) e Impuesto a la carne (2010). La dictadura del mercado ha exacerbado los mecanismos de control sobre los cuerpos y la feminización de la pobreza demuestra que son las mujeres quienes más sufren la exclusión y opresión de una regulación determinada por la acumulación capitalista. Sin embargo, en ambas novelas son los personajes femeninos quienes van a operar como potenciales agentes de cambio, generando pequeños "lugares de desacato" o esferas minoritarias de resistencia que desafiarán la lógica utilitaria y el dominio global del capital.

Palabras clave: Diamela Eltit, neoliberalismo, necropolítica, género, resistencia.

\begin{abstract}
This article reflects on coercion and exclusion practices that implement the necropolitics of the neoliberal model, through the analysis of the two novels by the Chilean author Diamela Eltit, Mano de obra (2002) and Impuesto a la carne (2010). The dictatorship of the market has exacerbated the mechanisms of control over the bodies and the feminization of poverty shows that women are the ones who suffer the most from the exclusion and oppression of a regulation determined by capitalist accumulation. However, in both novels, female characters operate as potential agents of change, generating small "places of contempt" or minority spheres of resistance that will challenge the utilitarian logic and global dominance of capital.
\end{abstract}

Keywords: Diamela Eltit, neoliberalism, necropolitics, gender, resistance. 


\section{Introducción}

"La estética también tiene un filo político" (Solorza, 2016: 80) afirma en una entrevista la escritora chilena Diamela Eltit y, sin lugar a dudas, esto se pone de manifiesto de manera muy clara a lo largo de su vasta producción literaria, en donde el compromiso social con aquellos que han sido expulsados del sistema se transforma en el motor que mueve su obra.

Dentro de la tradición literaria chilena, son varios los ejemplos en los que la narrativa aborda o se hace cargo de las tensiones políticas y económicas de su tiempo. Una obra representativa, en este sentido, correspondiente al primer tercio del siglo veinte, es Sub-terra: Cuadros mineros (1931), de Baldomero Lillo. Allí el autor evidencia la cruda realidad capitalista vinculada al negocio de la minería en Chile y la sobreexplotación de los cuerpos trabajadores.

Ya en las postrimerías del siglo veinte, un autor como Alberto Fuguet, que intentará distanciarse de la estética donosiana fuertemente ligada al boom literario latinoamericano de los sesenta $^{1}$, publicará Sobredosis (1990), un conjunto de cuentos en lenguaje coloquial y juvenil, signados precisamente por la "sobredosis" de libre mercado y el exceso de consumo de la nueva generación chilena. Pedro Lemebel, por su parte, cuya primera novela también sale a la luz en los años noventa: La esquina de mi corazón (1995), es otro de los escritores que habiendo desafiado los dispositivos políticos y económicos de control durante la dictadura y postdictadura ${ }^{2}$, reivindica mediante la crónica urbana, la experiencia de sujetos marginales -en este caso homosexuales y travestis de la periferia barrial o los barrios bajos de Santiago- encarnando deseos y violencias al interior de una sociedad marcada por la herencia dictatorial del libre mercado. Una obra más reciente como Fruta podrida (2007), de la escritora Lina Meruane, retoma de manera alegórica los fatídicos alcances del imaginario neoliberal y devela la indiferencia del sistema ante el aniquilamiento progresivo de los cuerpos.

Diamela Eltit comparte con estos escritores la práctica de una ficción que no es ajena al entramado socio-político en el que se gesta. Su narrativa se inscribe en la denominada "escena de avanzada", dentro del conjunto de obras de artistas y escritores que tiene lugar en el contexto

\footnotetext{
${ }^{1}$ El escritor chileno José Donoso se inscribe en la "cultura alta” de la tradición novelística moderna, cultor de un lenguaje narrativo culto e incluso poético, se distancia de las jergas coloquiales y populares contemporáneas.

${ }^{2}$ Lemebel incursionó, además, en el arte de la performance, conformando el dúo "Las yeguas del Apocalipsis", junto al poeta y artista chileno Francisco Casas. Ambos encarnaron una paródica versión femenina de los jinetes bíblicos, y solían presentarse sin previo aviso en eventos públicos para manifestarse artísticamente con un claro compromiso social y político. Una de sus "escandalosas" intervenciones fue en el encuentro de intelectuales que se realizó con Patricio Alwin, previo a las elecciones de 1989 en Chile, donde Las yeguas $[\ldots]$ se subieron al escenario con tacos y plumas, y desplegaron un lienzo en el que podía leerse "Homosexuales por el cambio".
} 
posterior al Golpe del 11 de septiembre de $1973^{3}$. Nelly Richard sitúa su obra en la corriente de neovanguardia, puesto que deconstruye la representación clásica mediante "una pulsión escritural que desborda los formatos canonizados por la tradición estética y re-estiliza hablas marginadas del campo de valoración socio literaria" (Richard, 1993: 42).

A lo largo del presente artículo, se intentará demostrar de qué manera la ficción literaria eltitiana opera mediante reiterados embates críticos al discurso neoliberal, apelando asimismo a una perspectiva de género. Si bien la crítica al neoliberalismo se pone de manifiesto en varias novelas de la autora, para este trabajo hemos seleccionado dos de sus obras más representativas vinculadas con la temática: Mano de obra (2002) e Impuesto a la carne (2010).

\section{El "milagro chileno": Surgimiento y continuidad del modelo de "libre mercado"}

Chile ha sido desde los años setenta un exponente clave del modelo neoliberal, importado en la región mediante una simbiosis de fuerzas que consolidó la unión entre intereses extranjeros y una política represiva instaurada en 1973 como consecuencia del Golpe de Augusto Pinochet al gobierno de Salvador Allende, lo que derivó en la caída de la Unidad Popular. ${ }^{4}$

Las influencias de la Escuela de Chicago, bajo la guía teórico-metodológica del economista Milton Friedman y las enseñanzas del profesor Arnold Herberger, signaron el devenir económico chileno desde los años setenta hasta la actualidad. Sus discípulos, conocidos como los "Chicago Boys", fueron un grupo de estudiantes de la Universidad Católica de Chile que, mediante un convenio con la Universidad de Chicago, viajaron becados para realizar allí sus estudios de postgrado en Economía, y regresaron luego con la idea de contribuir al desarrollo y progreso económico de su país.

Desde 1975 en adelante, el modelo llevado adelante por los Chicago Boys pasó a ser un complemento del autoritarismo e involucró el llamado "tratamiento de shock", un método que se oponía al gradualismo que sugerían otros economistas para contrarrestar la creciente inflación de aquellos años. Siguiendo las ideas motrices de Friedman, los discípulos de la Escuela de Chicago

\footnotetext{
${ }^{3}$ Eltit se ha desempeñado dentro de un arte experimental e interdisciplinario relacionado también con la performance. Junto al poeta Raúl Zurita, los artistas visuales Lotty Rosenfeld y Juan Castillo, y el sociólogo Fernando Balcells integró el CADA -Colectivo de Acciones de Arte- fundado en 1979. El grupo abogó por la fusión arte/vida y operó como manifestación artística disidente y expresión política opositora al discurso hegemónico, mediante la intervención artística del espacio público; sus intervenciones quedaron registradas en formato videográfico. En "Zona de dolor" (1980) es posible escuchar a la propia Eltit leyendo en un prostíbulo de una zona periférica de Santiago los avances de un texto que más tarde se convertiría en su primera novela: Lumpérica (1983). El video se encuentra disponible en el siguiente link: http://hemisphericinstitute.org/hemi/es/hidvl-additional-performances/diamela-eltit-zona-de-dolor [20/01/2017].

${ }^{4}$ La Unidad Popular, conformada en 1969 en reemplazo del Frente de Acción Popular, fue un pacto de fuerzas socialistas y de izquierda que llevó a Salvador Allende al poder, resultando presidente democráticamente electo de Chile en 1970.
} 
promovieron el libre mercado y el fortalecimiento de la empresa privada. Chile se transformó, así, en el experimento neoliberal latinoamericano catalogado en términos de "milagro", aunque la búsqueda del aparente equilibrio macroeconómico desestimó el costo social y los resultados altamente desfavorables para gran parte de la población:

“[el] ajuste que permitió la refundación del capitalismo chileno, recayó especialmente sobre los trabajadores y pensionados de las clases medias y bajas [...] un 30, 3\% del total de las familias chilenas no alcanzaban a consumir una canasta mínima, ubicándose en la extrema pobreza" (Delano y Traslaviña, 1989: 62-70).

El sentido contradictorio que el sintagma "libre mercado" adquirió en el contexto chileno evidenció desde los inicios una "trampa" o bien "una retórica y una ficción de libertad" (CárcamoHuechante, 2007: 14), tratándose de un modelo que fue instaurado mientras regía una completa privación de las libertades individuales fundamentales de sus ciudadanos.

Durante la transición democrática e incluso hasta la actualidad, se han sostenido las bases heredadas de la política económica implementada por los Chicago Boys. Recurriendo a Foucault podemos afirmar que se trata de una tecnología de gobierno en donde la "racionalidad de mercado" se extiende a todos los ámbitos, una razón gubernamental que obedece a una regulación biopolítica (2007: 218), a partir de la cual solo los cuerpos productivos o aptos para el consumo son los que cuentan en el nuevo estatuto del "ciudadano-cliente" (Moulián, 2015: 42). En términos de Žižek, esto implicaría una "violencia sistémica" o una represión encubierta que ha llegado a trascender el accionar de individuos concretos para transformarse en una forma de coerción global (2013: 23). Chile ha pasado de un Estado dictatorial a una "dictadura del mercado".

\section{Ficciones políticas, mercados caníbales: Mano de obra (2002) e Impuesto a la carne (2010)}

Como hemos mencionado al inicio del artículo, para Diamela Eltit toda estética "tiene un filo político" (Solorza, 2016: 80), y tanto Mano de obra (2002) como Impuesto a la carne (2010) develan las consecuencias negativas que el modelo económico genera sobre los cuerpos, a través de la representación del microcosmos del supermercado y del hospital, respectivamente, en tanto espacios en los que impera el capital. En ambos casos, los personajes se encuentran sometidos a un sistema de control biopolítico en donde la serialización y el logro del rédito económico a costa de la vida humana conforman una constante amenaza de muerte. La biopolítica se transforma, así, en necropolítica (del griego necro = muerte). Valverde Geffael afirma que "la necropolítica del neoliberalismo no necesita armas para matar a los excluidos. Por medio de sus políticas, los excluidos viven muertos en vida [...]" (2015: 18).

En las novelas seleccionadas, la necropolítica se pone de manifiesto mediante dos formas o modos de apropiación de los cuerpos: ya sea explotando la fuerza de trabajo en tanto capacidad 
productiva, es decir, la mano de obra; o a través de la denominada "clasificación funcional" (Rainhorn, 2015), que se abastece del cuerpo y sus partes en el nuevo mercado biotecnológico global, a través de bancos de sangre, transplantes de órganos, etc. Tanto uno como otro implican un cierto grado de canibalización ${ }^{5}$ de los cuerpos o bien lo que Rainhorn denomina un "mercado caníbal” (2015), en el que la lógica de la compra-venta, desligada de todo dilema ético, termina por consumir literalmente a los cuerpos.

En este último caso, que aborda el uso de diferentes partes del cuerpo como productos en sí mismos o mercancías, se trata de lo que Sayak Valencia denomina, a su vez, "mercado o capitalismo gore", en donde la violencia extrema instaura el necroempoderamiento a partir de un "uso predatorio de los cuerpos" (2010: 15). Hay aquí involucrada una cuestión de género, pues como veremos, este mercado caníbal o gore opera mediante prácticas coactivas que afectan y someten en mayor grado a las mujeres.

La novela Mano de obra se divide en dos partes: la primera, bajo el título "El despertar de los trabajadores (Iquique, 1911)", nos presenta el relato de un empleado alienado por la explotación laboral en el "súper" -supermercado-. El estado de cosificación se vuelve evidente: "Yo formo parte del súper -como un material humano accesible- y los clientes lo saben" (Eltit, 2004: 260) / "¿Quién soy? me pregunto de manera necia, y me respondo: "una correcta y necesaria pieza de servicio" (Eltit, 2004: 294). Reducido a mera cosa, sin la capacidad de articulación de un discurso político, bajo la constante mirada de los supervisores y la vigilancia de las cámaras del "súper", el trabajador ha perdido "su estatuto social de sujeto para devenir solo en MANO DE OBRA" (Olea, 2007: 17).

En Impuesto a la carne, este proceso de "desubjetivización” (Rainhorn, 2015), se produce al interior de un mercado hospitalario que comercializa con los cuerpos de sus internas. Las pacientes-protagonistas, una madre y una hija anónimas, afirman: "Ellas, las enfermeras, venden nuestra sangre y sólo una porción ínfima se destina a los exámenes de rutina que nos hacen" (Eltit, 2010: 66). En lugar de la explotación de la fuerza productiva, se trata, en este caso, de "un proletariado de «personas-objeto» cuya función sería vender y alquilar sus propios cuerpos para generar productos humanos que [aparentemente] mejorarían la salud de los más ricos" (Rainhorn, 2015: 29).

La alienación anclada en la repetición del trabajo serializado en Mano de obra, o la progresiva desubjetivización, contrasta con el contenido histórico-político presente en los subtítulos de la primera parte de la novela: "Verba Roja (Santiago, 1918)", "Luz y vida (Antofagasta, 1909)", “Autonomía y Solidaridad (Santiago, 1924)”, "El proletario (Tocopila,

\footnotetext{
${ }^{5}$ Se utiliza aquí el concepto de canibalismo no solo para hacer referencia a la relación voraz entre capital y trabajo, del mismo modo que lo hizo Marx en su famosa obra El Capital (Tomos III y VI), sino para analizar también una forma más explícita y actual del cuerpo-mercancía en el mercado de compra-venta de órganos y comercialización de bancos de sangre. Para mayores referencias sobre los diferentes usos y aplicaciones del concepto de canibalismo y sus derivados, sobre todo en América Latina, véase Jáuregui, Carlos (2008): Canibalia. Canibalismo, calibanismo, antropofagia cultural y consumo en América Latina. Madrid: Iberoamericana.
} 
1904)”, “Nueva Era (Valparaíso, 1925)”, “Acción directa (Santiago, 1920)”, "El obrero gráfico (Valparaíso, 1926)", y "La voz del mar (Valparaíso, 1920)", que traen a la memoria la prensa obrera y anarquista, promotora de los ideales libertarios durante el primer tercio del siglo veinte chileno, "con el peso heroico de tiempos en que la fuerza de trabajo [...] todavía producía, además de mercancías, revueltas e insurrecciones" (Richard, 2002: 2), un dispositivo de escritura que opera como "contramemoria" de los últimos treinta años chilenos (Carreño Bolívar, 2009a; 84). Curiosamente, en Impuesto a la carne el ideal anarquista también está presente, desde el momento de la concepción de ambas protagonistas: "Las dos nacimos anarquistas" (Eltit, 2010: 13), lo que motivará un comportamiento insubordinado y dará lugar a una constante rebeldía, a diferencia de los demás "pacientes sumisos" (Eltit, 2010: 12) del hospital.

El empleado de la primera parte de Mano de obra, lejos de la rebeldía anarquista, se mostrará consustancial al "proyecto de atomización social que promueve el neoliberalismo" (Moulián, 2015: 72), convirtiéndose en un cuerpo canibalizado por el régimen económico imperante mediante el "síntoma de la somatización de la relación laboral" (Tompkins, 2004: 119):

"Soy víctima de un mal que, si bien no es estrictamente orgánico, compromete a cada uno de mis órganos" (Eltit, 2004: 278) / "Mi deseo (mi último deseo) es derrumbarme en medio de un estrépito irreverente y así arrastrar conmigo a una hilera interminable de estantes para que las mercaderías sean, finalmente, las que me lapiden" (Eltit, 2004: 280).

La extrema cosificación de los cuerpos es lo que activa la impronta necropolítica. Tanto en Mano de obra como en Impuesto a la carne, el sacrificio que impone el rédito económico supone llevar la vida al límite, en el primer caso suprimiendo las necesidades más básicas, como orinar: "Atenderemos [...] a lo largo de veinticuatro horas. Imposible la orina porque yo no puedo ausentarme ni un instante de la acometida humana que se nos cayó encima" (Eltit, 2004: 291); mientras que, en el segundo caso, el mercado médico caníbal motivará irónicamente a la madre a intentar vender alguna parte de su cuerpo para sobrevivir: "Podría, dice mi mamá, vender uno o dos o tres dedos porque en realidad no son demasiado importantes, pero todavía no hay un espacio, un verdadero espacio para los dedos, ¿te das cuenta? No se les ha ocurrido o no se puede o no quieren dedos, no sé” (Eltit, 2010: 138).

No es casual que, en Mano de obra, la progresiva degradación de la salud del empleado se ponga de manifiesto en consonancia con una simbólica feminización: "Después de todo soy un hombre aunque, en algún sentido (lo sé), termino enredado a la imagen con que se define una mujer. Mujercita yo" (Eltit, 2004: 276). Es simbólica si tenemos en cuenta dos fenómenos estrechamente vinculados dentro del modelo neoliberal: la precarización de la existencia y la feminización del trabajo. Como sabemos: "[la] desregulación de mercado laboral, [la] expansión del empleo denominado precario y [la] difuminación entre empleo formal e informal [...] han estado históricamente asociadas [...] a los trabajos desarrollados por mujeres en lo doméstico, en la economía sumergida y en las escalas más bajas del mercado laboral" (Precarias a la deriva, 2006: 107). 
En este punto, resulta pertinente traer a colación la relación entre capitalismo y patriarcado, así como entre capitalismo y discriminación racial o étnica. El análisis o abordaje del feminismo interseccional, ${ }^{6}$ entendido como el estudio de las relaciones de poder en la conformación de subjetividades a partir de la interacción de diversas categorías: raza, clase, género, entre otras, sirve para dar cuenta "de la multidimensionalidad de los procesos de exclusión social" (Cruells López, 2015: 11). Federici sostiene que “el capitalismo, en tanto sistema económico-social, está necesariamente vinculado con el racismo y el sexismo [...] denigrando la "naturaleza" de aquellos a quienes explota: mujeres, súbditos coloniales [...] inmigrantes desplazados por la globalización" (2010: 32).

Es en la segunda parte de la novela, bajo el título "Puro Chile", donde el racismo y el sexismo, asociados a la lógica neoliberal, adquieren todavía más relevancia. Absolutamente despojado del eco nostálgico de un pasado épico-revolucionario, como sucedía con los subtítulos de la primera parte, aquí el neoliberalismo se presenta en su fase más actual y descarnada, "en la máxima desarticulación de los mínimos vínculos comunitarios" (Olea, 2007: 12). Se trata de los "sujetos flexibles del capitalismo avanzado" (Franco, 2007: 146), para quienes la frontera entre lo público y lo privado se confunde. Así, la casa en la que viven los empleados y empleadas del "súper" es un fiel reflejo del orden jerárquico y coactivo en el que trabajan: en la casa no se admiten "cesantes ni enfermos" (Eltit, 2004: 307).

El racismo resurge aquí como consecuencia de un poder implícito que legitima el liderazgo de Enrique, encargado de organizar tareas y establecer normativas en lo doméstico: "Porque Enrique era alto, más blanco, más entero, más visible, más persona” (Eltit, 2004: 323). Jean Franco afirma que "la blancura sobrevalorizada en una sociedad en gran parte mestiza o indígena determina [...] diferencias" (2007: 146). ${ }^{7}$ Esto devela una jerarquía en la que algunos cuerpos son "en apariencia" más funcionales que otros, menos "desechables" que otros y a los que, finalmente, se debe "hacer sobrevivir" (Oyarzún, 2010) más que a otros. El racismo está también presente en Impuesto a la carne, donde el personaje de la hija afirma: "Nos dicen negras curiches" (Eltit, 2010: 33). Resulta pertinente reparar en el uso de la palabra "curiche", cuya etimología proviene del mapudungun, la lengua de los mapuche -población originaria de Chile- compuesta por "curi" (negro) y "che" (gente). El apelativo "negras curiches" incurriría en una redundancia; sin embargo, sirve para enfatizar que la diferencia en lo que respecta al tono de la piel, se asocia al origen indígena de las protagonistas. Son cuerpos que contrastan con aquellos normativamente

\footnotetext{
${ }^{6}$ El término "interseccionalidad" aparece formalmente en 1989, en un artículo publicado en EE. UU. por Kimberle Crenshaw: "Demarginalizing the Intersection of Race and Sex: A Black Feminist Critique of Antidiscrimination Doctrine, Feminist Theory and Antiracist Politics". Sin embargo, la existencia de un análisis de este tipo estaba ya presente en el trabajo que venían desarrollando feministas como bell hooks, Angela Davis o Gloria Anzaldúa, entre otras. El enfoque de Crenshaw se centra en la experiencia de mujeres negras que se encuentran afectadas por una desigualdad en la que variables de clase, raza y género interactúan entre sí, dando lugar a una triple discriminación.

${ }^{7}$ Para profundizar sobre los orígenes del racismo en Chile y la ideología de un mestizaje "blanqueado" que ha intentado negar el componente indígena, véase Montecino Aguirre, Sonia (2012): Madres y huachos. Alegorías del mestizaje chileno. Santiago de Chile, Catalonia.
} 
esperables de los médicos-supervisores, "altos y albos"; la madre y la hija en cambio, son "bajas, demasiado morenas" (Eltit, 2010: 33).

Es asimismo evidente que "los cuerpos que importan" o que cuentan con algún privilegio dentro del sistema no son tampoco los cuerpos percibidos como femeninos. Siguiendo la teoría de la performatividad de Butler y su concepción de la corporalidad en tanto "efecto del poder" (2002: 64), es posible afirmar que el género es producto de ciertas prácticas discursivas que se materializan en los cuerpos para volverlos socialmente inteligibles.

Se trata de una "ficción reguladora" que determina la "validez" o "legitimidad" de los cuerpos, clasificándolos dentro de las estrictas categorías de lo femenino y lo masculino; y sanciona aquellos que no reproducen las prácticas que sostienen el ideal identitario. Los personajes femeninos en la segunda parte de Mano de obra son víctimas de la explotación del sistema y se encuentran cosificados no solo en tanto mano de obra, sino en función de sus características sexo-genéricas $^{8}$, viéndose relegados a roles estereotipados de género: Isabel, que trabaja como promotora en el "súper", es obligada por sus propios compañeros a cuidar su apariencia y mantenerse como cuerpo deseable para satisfacer los bajos instintos de un viejo supervisor y obtener, de esta manera, algunos beneficios laborales para el grupo.

Es duramente criticada cuando, ante el exceso de presión en el trabajo, y como consecuencia de su intento por promocionar tres productos en simultáneo -no solo para su propia supervivencia sino para darle de comer a su guagua [bebé]- cae en una depresión que la lleva a "dejarse estar": "No sé qué le pasa a esta huevona [...] parece que lo único que buscara es que nos caguen. Ni siquiera se preocupa de calentar a los viejos culiados" (Eltit, 2004: 332).

Otro de los personajes femeninos que sufre una "violencia generizada" o "engendered violence" (De Lauretis, 1987: 43) -como consecuencia de esta lucha desigual de fuerzas que privilegia a los sujetos percibidos como masculinos- es Gloria, que, ante la pérdida de su empleo a causa de la flexibilidad laboral, pacta con los trabajadores residentes permanecer en la casa a cambio de realizar los quehaceres domésticos, un trabajo invisibilizado y despojado de todo valor económico. Históricamente se ha ocultado "el trabajo familiar doméstico y su articulación con el sistema capitalista" (Carrasco, 2006: 33), lo cual se vuelve evidente en el caso de Gloria por su desplazamiento obligado del espacio central de la casa: "Naturalmente [...] debía dejar su cuarto y empezar a dormir en la minúscula pieza del fondo" (Eltit, 2004: 202). A ello se le suma la explotación sexual a la que es sometida, ya que su labor "doméstica" no consistirá solamente en cocinar o limpiar, sino también en servir sexualmente a los hombres de la casa.

Sonia, por su parte, otra de las co-inquilinas, que en principio trabaja como cajera del "súper", explotada en turnos excesivos e inhumanos: "ni mear podía [...] Especialmente ella que trabajaba encadenada a la caja" (Eltit, 2004: 318), es desplazada en dos oportunidades de su

\footnotetext{
${ }^{8}$ Con respecto a la diferenciación entre sexo y género, Butler arremete contra todo esencialismo y desde un materialismo constructivista afirma que la categoría de sexo, históricamente asociada a lo biológico, es también un constructo cultural: "quizás esta construcción denominada "sexo" esté tan culturalmente construida como el género; de hecho, quizás siempre fue género, con el resultado de que la distinción entre sexo y género no existe como tal" (Butler, 2007: 55).
} 
puesto, relegada a condiciones mucho más precarias que las del resto de sus compañeros: "La pobre (pobrecita) Sonia que de un instante para otro la habían empujado a trabajar atrás [...] a la carnicería del súper" (Eltit, 2004: 326). Como afirma Ocasio-Rivera, "el sistema capitalista, si bien abre un espacio a la mujer como otro ente que vende su mano de obra, sigue perpetuando la [...] estructura patriarcal que la subyuga a una explotación aún mayor que al hombre" (2015: 109). El segundo desplazamiento de Sonia es hacia la pescadería, luego de sufrir la mutilación de su dedo índice en la repetitiva tarea de trozar pollos. Cada traslado supone un paso más en su degradación corporal y subjetiva, que roza la animalización: "el último traslado posible [...] la condujo directamente a la sección helada de la pescadería [...] estigma indesmentible [...] donde se acumulaban los olores finales y proscritos [...] la tristeza [...] la embargaba mientras caminaba [...] con una impronta de mansedumbre ovina [...]" (Eltit, 2004: 347).

La animalización y la reducción del cuerpo femenino a su función sexual y reproductiva es otra de las consecuencias derivadas de la mercantilización. Federici revela que la reproducción ha sido en diversos momentos y contextos geopolíticos "directamente puesta al servicio de la acumulación capitalista” (2010: 139), lo que derivó en repetidos genocidios históricamente conocidos como "caza de brujas". Las víctimas siempre han sido mujeres, en general pobres, consideradas "herejes" por transformarse en contestatarias del sistema al intentar decidir libremente sobre sus cuerpos. En Impuesto a la carne los médicos disponen sexualmente de los cuerpos de sus pacientes y el personaje de la hija es producto de una violación: "Mi madre dice que ante la presencia del primer médico sintió algo extraño, único [...] Dice que en ese momento entendió que una parte crucial de sí misma se había modificado, porque hasta ese día ella era inocente como una virgen o una lega o una tonta y me asegura que el médico la sacó de ese estado" (Eltit, 2010: 23).

En los nuevos mercados biotecnológicos también la función reproductiva o el vientre subrogado es un bien de consumo; sin embargo, estas mujeres son herederas de una falla originaria, algo que ya traen en su sangre "anárquica": "como si fuéramos una infección incandescente o un titilante y fraudulento deshecho" (Eltit, 2010: 20), lo que hace que los médicos intenten por todos los medios impedir que se reproduzcan para preservar "el buen estado general de salud" (Eltit, 2010: 11) de la "patria hospitalaria". De hecho, uno de ellos trata de provocarle un aborto a la madre para evitar el nacimiento de la hija, pero esta, de todos modos, se aferra a la vida. Para Butler toda "ficción reguladora" genera, como en este caso, un "exterior constitutivo" (2007: 73), representado por aquellos cuerpos que escapan a la matriz homogeneizante de las normativas de género y encarnan, por lo tanto, un potencial peligro para el sistema.

Es interesante reparar en el vínculo simbiótico-mutualista que se genera entre madre e hija, ese nacimiento hace que la madre renazca convirtiéndose en un órgano vital de la hija, lo cual da cuenta de la fuerza que las mancomuna para resistir:

"Mi organomadre pretende amplificar su lucidez en la irreprimible historia de mi cuerpo" (Eltit, 2010: 183) / "Velamos la una por la otra, nos desvelamos la una por la otra porque yo sé que hemos durado 
tanto, ¿cuántos?, ¿doscientos años?, lo hemos hecho por la forma de estar una dentro de la otra, atentas y ensambladas [...]" (Eltit, 2010: 52)

Se trataría de una "empatía radical", una alianza de vulnerabilidades para "hacer frente [...] a la necropolítica [...], solidaridad y empatía que se podrían convertir en revuelta" (Valverde Gefaell, 2015: 14-15).

En Mano de obra, la potencialidad de la "empatía radical" se pierde ante el constante desaliento a la mancomunión y sindicalización de los trabajadores: Alberto es denunciado por Gloria y despedido por los supervisores, ante el intento de sindicalizarse. Aunque, sin duda, la mayor traición dentro del grupo la comete Enrique, el líder de la casa, quien es ascendido a supervisor y, una vez en el poder, despide sin remordimientos a todos sus compañeros, echándolos también de la casa. La necropolítica neoliberal parece conducir a la eliminación del semejante en pos de la propia supervivencia, tratándose de un "hacer sobrevivir" (Oyarzún, 2010) que necesariamente implica la canibalización del otro, una estrategia para desmovilizar a los proletarios e impedir la autoorganización o la alianza de vulnerabilidades (Valverde Gefaell, 2015).

Esta necesidad de legitimación y consolidación del modelo neoliberal mediante el desaliento de los lazos de solidaridad entre colegas no impide, sin embargo, la existencia de algunos "lugares de desacato" (Forcinito, 2010: 104) o desobediencia dentro del orden aséptico del súper: un exceso de vida en estrecha relación con lo abyecto (orina, sangre menstrual, excrementos [...]) que transgrede la lógica utilitaria de la ganancia. El cuerpo femenino se presenta, en este sentido, como recurrente agente de insubordinación: "Sonia se ponía la toalla entre sus piernas [...] le había bajado la regla y la sangre corría arrastrando unos coágulos densos, una masa viscosa y móvil [...]" (Eltit, 2004: 347). Estos flujos vitales y desterritorializantes (Deleuze y Guattari, 2000), desafían una y otra vez [...] la asepsia de un modelo de conductas y apariencias supuestamente inalterables que recomienda el «súper»" (Richard, 2002: 3).

A ello se suma el final abierto que presenta la novela, con la desarticulación jerárquica del grupo de trabajadores expulsados del súper y de la casa, que insinúa, como bien lo observa Scarabelli: "la posibilidad de un nuevo comienzo [...] una nueva esperanza" (2013: 15): "salíamos desolados de la casa hacia lo que se iba a convertir en un nuevo destino para nosotros [...] Ya pues, huevones, caminemos, caminemos, demos vuelta la página” (Eltit, 2004: 360). Esto abre una pequeña posibilidad de desvío o de fuga con respecto a los alcances del poder hegemónico del mercado. Aunque ya sin la trascendencia épica de los grandes gestos revolucionarios del pasado, son estas pequeñas esferas minoritarias de resistencia e

\footnotetext{
${ }^{9}$ Los irónicos doscientos años de vida durante los cuales las protagonistas anónimas de esta historia han sido sometidas a todo tipo de vejaciones y han resistido en un espacio claramente opresivo, remiten de manera evidente al Bicentenario de la Independencia de Chile, en 2010, el mismo año de publicación de la novela. Implícita sobrevuela la pregunta: ¿independencia real o ficticia? Pues habiéndose declarado independiente del primer colonialismo, marcado por la Conquista, ha terminado sometido a otro, el neocolonialismo de la globalización y del "libre mercado".
} 
insubordinación: "Vamos a cagar a los maricones que nos miran [...] como si no fuéramos chilenos como todos los demás" (Eltit, 2004: 360), las que desafían la lógica utilitaria y el dominio global del capital.

En Impuesto a la carne, las posibilidades de resistencia y rebelión al sistema son todavía mayores: las protagonistas, oponiéndose a los médicos y enfermeras de un "mercado caníbal" que trafica órganos y vende sangre, no cederán en la búsqueda de una "renovadora sociedad de resistencia". Madre e hija demuestran que en todo sistema hay un punto de quiebre, una fuerza capaz de desobedecer y de no ser colonizada, una fuga de poder a partir de la cual las excluidas son capaces no solo de resistir, sino de convertirse en "potencia de transformación" (Negri, 2009: 120) de lo dado: "Es ella, sí, mi mamá [... la que quiere controlar y quizás amotinar a las operadas UUUUUUUUU ulula mi madre [...] UUUUUUUUU como un perro hambreado que no se ha resignado ni a su vida ni a su muerte [...] [y finalmente] por una agitación incontrolable UUUUUUUUUU ululan las pobres operadas organizando la jauría” (Eltit, 2010: 184).

Surge, de esta manera, un poder descentralizado o una micropolítica que altera momentáneamente la asimetría del mercado. Se trata de "cuerpos [que] con [...] su presencia, ponen en evidencia la verdad sobre las injusticias de la sociedad capitalista neoliberal. Son cuerpos que resuenan [...] que gritan" (Valverde Gefaell, 2015: 124), cuerpos peligrosos que incomodan, y por "efecto contagio" transforman su agencia y resistencia en fuerza colectiva, de modo que las demás "pacientes" comienzan, a su vez, a rebelarse.

\section{Conclusiones}

Las dos novelas de Diamela Eltit aquí analizadas dan cuenta de los modos en que el poder hegemónico del mercado oprime a los sujetos, operando mediante una violencia económica que estigmatiza los cuerpos "no rentables" y los excluye del sistema. Aun así, es posible encontrar pequeños focos de resistencia en los intersticios, ese "tercer espacio" (Bhabha, 1990) que determina la frontera entre el adentro y el afuera del sistema, definido por la diferencia y la otredad. Son los personajes femeninos quienes en mayor grado encarnan esta diferencia otrificante, derivada no solo de cuestiones de género y clase -tratándose de mujeres pobres- sino de etnia, ya que se pone de manifiesto el origen indígena en una sociedad de mayoría mestiza. Racismo, capitalismo y patriarcado actúan en forma conjunta potenciando la dinámica neoliberal. En Impuesto a la carne, la práctica de una resistencia materializada por el personaje de la madrehija, dos en una, da lugar a una unión de vulnerabilidades que deviene en grito o estallido, una clara "afirmación colectiva de dignidad" (López Petit, 2015: 14).

En Mano de obra, la resistencia al sistema se encuentra neutralizada por la fuerza de un capitalismo avanzado que intenta equiparar a cualquier costo la rentabilidad de los cuerpos dentro de la exacerbada lógica de compra-venta. Pero incluso en este contexto, una micropolítica de 
resistencia es posible, y los cuerpos que se rebelan ante la injusticia y la explotación son, también en este caso, los percibidos como femeninos, aquellos que se intenta ocultar cuando se convierten en portadores de una abyección o de una enfermedad que afecta la rentabilidad aséptica del sistema. El final abierto de la historia alimenta una incipiente esperanza de cambio, mientras que la estructura circular de la obra, al anticipar un nuevo comienzo, juega especularmente con la necesidad implícita de un retorno a esa lucha colectiva que rememoran los subtítulos de la primera parte. Una lucha que ya no puede ni debe ignorar la situación desigual de las mujeres en el acceso al capital.

\section{BIBLIOGRAFÍA}

- Agamben, Giorgio (2003): "El campo de concentración como paradigma biopolítico de lo moderno". En: Giorgio Agamben: Homo sacer. El poder soberano y la nuda vida. Valencia: PreTextos, pp. 151-181.

- Bhabha, Homi (1990): "The Third Space". En: Jonathan Rutherford (coord.): Identity, Community, Culture, Difference. Londres: Lawrence and Wishart, pp. 207-221.

- Blanco, Fernando (2006): "Poéticas de alienación y muerte en Mano de Obra”. En: Bernardita Llanos (coord.): Letras y proclamas: la estética literaria de Diamela Eltit. Santiago: Cuarto Propio, pp. 171-199.

- Cárcamo-Huechante, Luis (2007): Tramas del mercado: Imaginación económica, cultura pública y literatura en el Chile de fines del siglo veinte. Santiago: Cuarto Propio.

- Butler, Judith (2002): Cuerpos que importan. Sobre los límites materiales y discursivos del “sexo”. Buenos Aires: Paidós.

. (2007): El género en disputa. El feminismo y la subversión de la identidad. Barcelona:

Paidós.

- Carrasco, Cristina (2006): “La economía feminista: una apuesta por otra economía”. En: María Jesús Vara (coord.): Estudios sobre género y economía. Madrid: Akal, pp. 29-62.

- Carreño Bolívar, Rubí (2009a): "La pequeña labor: Las redes del trabajo del fundo al supermercado”. En: Ruby Carreño Bolívar: Memorias del nuevo siglo: jóvenes, trabajadores y artistas en la novela chilena reciente. Santiago: Cuarto Propio, pp. 79-105.

. (2009b): "La ciudad de los trabajadores: Memoria, patrimonio y literatura en Eltit (2002), Rivera Telier (2002) y Lorenzini (2003)". En: Ruby Carreño Bolívar: Memorias del nuevo siglo: jóvenes, trabajadores y artistas en la novela chilena reciente. Santiago: Cuarto Propio, pp. 5978.

- Crenshaw, Kimberle (1989): "Demarginalizing the Intersection of Race and Sex: A Black Feminist Critique of Antidiscrimination Doctrine, Feminist Theory and Antiracist Politics". En: University of Chicago Legal Forum, pp. 139-167. Disponible en: 
http://chicagounbound.uchicago.edu/cgi/viewcontent.cgi?article=1052\&context=uclf [20/01/2017].

- Cruells López, Marta (2015): La interseccionalidad política: Tipos y factores de entrada en la agenda política, jurídica y de los movimientos sociales. Tesis de doctorado, Doctorat en Politiques Públiques de la Universitat Autónoma de Barcelona. Disponible en: http://tesisenred.net/handle/10803/288224 [20/01/2017].

- De Lauretis, Teresa (1987): "The Violence of Rhetoric. Considerations on Representation and Gender”. En: Teresa de Lauretis (coord.): Technologies of Gender. Essays on Theory, Film and Fiction. Bloomington: Indiana University Press, pp. 31-51.

- Delano, Manuel y Hugo Traslaviña (1989): La herencia de los Chicago Boys. Santiago: Las Ediciones del Ornitorrinco.

- Deleuze, Gilles y Félix Guattari (2000): "20 noviembre 1923. Postulados de la lingüística”. En: Gilles Deleuze y Félix Guattari: Mil mesetas. Capitalismo y esquizofrenia. Valencia: PreTextos, pp. 81-116.

- Del Solar Felipe y Pérez, Andrés (2008): Los anarquistas. Presencia libertaria en Chile. Santiago: RIL.

- Douglas, Mary (1973): “La impureza ritual”. En: Mary Douglas: Pureza y peligro. Un análisis de los conceptos de contaminación y tabú. Madrid: Siglo Veintiuno, pp. 21-61.

- Eltit, Diamela [2002] (2004): "Mano de obra". En: Diamela Eltit: Tres novelas. México: Fondo de Cultura Económica, pp. 246-360. . (2010): Impuesto a la carne. Buenos Aires: Eterna Cadencia.

- Federici, Silvia (2010): Cáliban y la bruja. Mujeres, cuerpo y acumulación originaria. Madrid: Traficantes de sueños.

- Forcinito, Ana (2010): "Desintegración y resistencia: Corporalidad, género y escritura en Mano de obra de Diamela Eltit”. En: Anclajes, vol. 14, nº 1, pp. 91-107. Disponible en: http://dialnet.unirioja.es/servlet/articulo?codigo=4794293 [03/01/2017].

- Foucault, Michel (2007): Nacimiento de la biopolítica. Buenos Aires: Fondo de Cultura Económica.

- Franco, Jean (2007): "Malas palabras. Sobre Mano de obra de Diamela Eltit”. En: Antonio Gómez (coord.): Provisoriamente. Textos para Diamela Eltit. Rosario: Beatriz Viterbo, pp. 143152.

- Jáuregui, Carlos (2008): Canibalia. Canibalismo, calibalismo, antropofagia cultural y consumo en América Latina. Madrid: Iberoamericana.

- Lázzara, Michael (2009): "Estrategias de dominación y resistencia corporales: Las biopolíticas del mercado en Mano de obra de Diamela Eltit”. En: Rubí Carreño Bolívar (coord.): Diamela Eltit: redes locales, redes globales. Santiago: Pontificia Universidad Católica de Chile, pp. 155-164. 
- López Petit, Santiago (2015): "Prólogo". En: Clara Valverde Gefaell. De la necropolítica neoliberal a la empatía radical. Violencia discreta, cuerpos excluidos y repolitización. Barcelona: Icaria, pp. 11-14.

- Montecino Aguirre, Sonia (2012): Madres y huachos. Alegorías del mestizaje chileno. Santiago: Catalonia.

- Moulián, Tomás (2015): El consumo me consume. Santiago: LOM.

- Núñez-Méndez, Eva (2008): "La Diamela Eltit de Mano de obra: mística de los trabajadores". En: Hispanófila, vol. 152, University of North Carolina at Chapel Hill, pp. 87-100. Disponible en: https://muse.jhu.edu/issue/25657 [04/02/2017].

- Negri, Antonio (2009): “El monstruo político. Vida desnuda y potencia”. En: Gabriel Giorgi y Fermín Rodríguez (coords.): Ensayos sobre biopolítica. Buenos Aires: Paidós, pp. 93-139.

- Ocasio, Rivera, Wanda (2012): "Blood, organs and other tissues for sale: Diamela Eltit's Impuesto a la carne and the afterwards of the neoliberal development in Latin America". En: Hispanic Studies Publications, vol. 8, pp. 1-22. Disponible en: http://ir.lib.uwo.ca/hipanicpub/8 [08/02/2017].

. (2015): Metáforas extremas del neoliberalismo en la Literatura Latinoamericana. Tesis

del Doctorado en Filosofía. Universidad de Illinois. Disponible en: http://www.ideals.illinois.edu/bitstream/handle/2142/78465/OCASIO-RIVERA-

DISSERTATION-2015.pdf?sequence=1 [12/01/2017].

- Olea, Raquel (2007): “Mano de obra. La dislocación de lo social”. En: Alfredo Castro: Mano de obra / Diamela Eltit (adaptación para teatro). Santiago: Cuarto Propio, pp. 9-13.

- Oliver, Felipe (2015): “Mano de obra. El supermercado por dentro". En: La Palabra, no. 25, pp. 1-6. Disponible en: http://revistas.uptc.edu.co/index.php/la_palabra/article/view/3206/2930 [24/01/2017].

- Oyarzún, Kemy (2010): “«No tengo vida»: Inscripciones biopolíticas en la subjetividad contemporánea”. En: Isabel Cassigoli y Mario Sobargo (coords.): Biopolíticas del sur. Santiago: ARCIS, pp. 361-373.

- Precarias a la deriva (2006): "Precarización de la existencia y huelga de cuidados". En: María Jesús Vara (coord.): Estudios sobre género y economía. Madrid: Akal, pp. 104-134.

- Rainhorn, Jean-Daniel (2015): “Globalization and the Misuses of Biothecnologies: Back to Cannibalism?”. En: Jean-Daniel Rainhorn y Samira El Boudamoussi (coords.): New Cannibal Markets. Globalization and the Commodification of the Human Body. Paris: Éditions de la Maison des Sciences de 1'Homme, pp. 13-33.

- Richard, Nelly (1993): "Tres funciones de escritura: Deconstrucción, simulación, hibridación”. En: Juan Carlos Lértora (coord.): Una poética de literatura menor: La narrativa de Diamela Eltit. Santiago: Cuarto Propio, pp. 37-51. . (2002): "Tres recursos de emergencia: las rebeldías populares, el desorden somático y la palabra extrema”. Disponible en: http://letras.s5.com/eltit091202.htm [04/02/2017]. 
- Scarabelli, Laura (2013). "La ciudad-supermercado. Mano de obra de Diamela Eltit". En: P. Spinato Bruschi y J. J. Martínez (coords.): Cuando quiero hallar las voces, encuentro con los afectos: Studi di iberistica offerti a Giuseppe Bellini. Roma: Consiglio Nazionale delle Ricerche, pp. 10-25.

- Solorza, Paola Susana (2016). "Entrevista a Diamela Eltit: una literatura no consensual. Cuerpo, lugares border y resistencia". En: Anclajes, vol. XX, nº 1, pp. 79-89. Disponible en: http://www.scielo.org.ar/pdf/anclajes/v20n1/v20n1a05.pdf [12/01/2017].

- Soto, Ángel (2012) (coord.): Un legado de libertad. Milton Friedman en Chile. Santiago: Fundación para el progreso, Instituto Democracia y Mercado, Atlas Economic Research Foundation.

- Tompkins, Cynthia (2004): "La somatización del neoliberalismo en Mano de obra de Diamela Eltit”. En: Hispamérica, Año XXXIII, nº. 98, pp. 115-123.

- Valencia, Sayak (2010): Capitalismo gore. Santa Cruz de Tenerife: Melusina.

- Valverde Gefaell, Clara (2015): De la necropolítica neoliberal a la empatía radical. Violencia discreta, cuerpos excluidos y repolitización. Barcelona: Icaria.

- Vara, María Jesús (2006): “Empleo femenino en las cadenas de producción global”. En: María Jesús Vara (coord.): Estudios sobre género y economía. Madrid: Akal, pp. 63-82.

- Žižek, Slavoj (2013): Sobre la violencia. Seis reflexiones marginales. Buenos Aires: Paidós.

- Zunini, Patricio. 2011: "La unión madre -hija es la pareja más débil de la cultura" -Entrevista

a Diamela Eltit. Disponible en: http://blog.eternacedencia.com.ar/archives/2011/13385 [20/12/2016]. 